Pia Schnorpfeil · Alexander Noll · Petra Wirtz

Renate Schulze · Ulrike Ehlert · Karl Frey

Joachim E. Fischer

\title{
Assessment of exhaustion and related risk factors in employees in the manufacturing industry - a cross-sectional study
}

\begin{abstract}
Objectives: Vital exhaustion, a construct overlapping with burnout, is an independent risk factor for adverse health outcomes, including cardiovascular disease. We aimed to assess vital exhaustion in employees in the manufacturing industry and identify work characteristics associated with exhaustion. Methods: Cross-sectional study. A stratified, representative random sample of employees from a manufacturing plant for airplane parts and assemblies was invited $(n=647)$, of whom 537 employees $(83 \%$ accrual) volunteered to participate. Scores obtained by the nine-item Shortened Maastricht Exhaustion Questionnaire were compared with the mental and physical summary scales of the SF-12 General Health Survey and to a list of 20 health complaints. Pathogenic and salutogenic work characteristics were assessed by the self-reported 52item, 13-subscale SALSA questionnaire. Results: Vital exhaustion correlated with the mental summary score of the SF-12 and the number of health complaints and was positively associated with age. Exhaustion was not associated with gender, position (socio-economic status) or being on a wage (paid per completed item up to a contracted amount) or salary (payment as fixed monthly income). The instrument identified departments with high levels of exhaustion. Of the observed variance in exhaustion, $29 \%$ was explained by age, department, and five work characteristics: High levels of exhaustion (score >10) were related to excessive workload or
\end{abstract}

P. Schnorpfeil $\cdot$ A. Noll $\cdot$ P. Wirtz $\cdot$ K. Frey $\cdot$ J.E. Fischer $(\bowtie)$ Institute of Behavioral Sciences,

Swiss Federal Institute of Technology,

Turnerstrasse 1, 8092 Zurich, Switzerland

E-mail: fischer@ifv.gess.ethz.ch

Tel.: +41-632-5853

Fax: + 41-632-1219

R. Schulze

EADS Deutschland GmbH, Werk Augsburg, Germany

U. Ehlert

Department of Clinical Psychology,

University of Zurich, Switzerland qualitative demands (scoring in the highest quartile; OR $_{\text {adj }} 7.5$; 95\% CI 2.4-23), to adverse physical work conditions $\left(\mathrm{OR}_{\mathrm{adj}} 6.9 ; 95 \% \mathrm{CI} 2.2-21\right)$, to adverse coworker behavior $\left(\mathrm{OR}_{\mathrm{adj}} 4.8 ; 95 \% \mathrm{CI} 1.4-16\right)$, to qualification potential $\left(\mathrm{OR}_{\mathrm{adj}} 0.32 ; 95 \%\right.$ CI $\left.0.11-0.97\right)$, and to social support by co-workers $\left(\mathrm{OR}_{\mathrm{adj}} 0.34 ; 95 \% \mathrm{CI}\right.$ 0.13-0.99), respectively. Conclusions: The nine-item instrument allows rapid screening of employees for selfreported levels of exhaustion. Besides physical work conditions and workload, absence or presence of social support by co-workers is strongly associated with exhaustion.

Keywords Vital exhaustion - Subjective health status • SF-12 - Work characteristics $\cdot$ Risk factors

Abbreviations $S F-12$ Short version of the Short Form-36 General Health Survey - SALSA Salutogenic subjective work analysis $\cdot S F-36$ Short Form-36 General Health Survey $\cdot 95 \%$ CI 95\% Confidence interval · $O R_{a d j}$ Adjusted odds ratio $\cdot E A D S$ European Aeronautic Defense and Space Company

\section{Introduction}

In healthy men vital exhaustion is a potent risk factor for death from cardiovascular disease (Cole et al. 1999; Appels 1999; Appels and Mulder 1988). Vital exhaustion is characterized by a combination of fatigue, lack of energy, loss of libido, feelings of hopelessness and increased irritability (Appels 1997, 1990). Considerable overlap exists between exhaustion and burnout (Weber and Jaekel-Reinhard 2000; Appels and Schouten 1991), and probably with depression (Kopp et al. 1998). Little is known about the extent and prevalence of vital exhaustion in employees in the manufacturing industry. More data are available on burnout (Maslach et al. 2001), particularly for healthcare personnel (Edwards et al. 2000; Leiter and Harvie 1996). During the past two decades adverse work characteristics that increase the 
risk of burnout in healthcare professionals have been identified (Payne 2001; Hannigan et al. 2000; Demerouti et al. 2000). Burnout may ultimately lead to absenteeism, reduced job performance and an increased risk of psychosomatic or psychiatric disorders.

In the economic context of globalization, the industry attempts to meet the demands for increasing productivity by rapid cycles of restructuring, merging and rationalizing. The associated changes in the working environment impose hitherto unknown threats to health, namely of "psychosocial" origin (Landsbergis et al. 1999). These hazards are not captured by traditional methods of occupational medicine. Although prospective data are scarce, it is conceivable that highly exhausted employees will be less productive than their non-exhausted colleagues. Thus, ameliorating exhaustion and minimizing its heterogeneity within a company should be a primary target both from an economical as well as from a public health perspective. Unfortunately, methods that provide for rapid screening of exhaustion have not been tested for industrial working populations.

To address this matter, we conducted a cross-sectional study in a stratified random sample of employees of an industrial plant. The primary aim was to test the validity and usefulness of a pre-validated short questionnaire to identify exhausted individuals and groups. The secondary aim was to identify work characteristics that explain part of the observed variance in levels of exhaustion.

\section{Methods}

\section{Participants}

The study was conducted in a manufacturing plant for airplane parts and assemblies. A stratified representative random sample of the 1,760 employees was invited to participate $(n=647)$. Strata consisted of departments, with sampling of every second person in small departments and of every fourth person in large departments ( $>50$ employees). Of these invited employees, 537 volunteered to participate. Time for participation was paid as working time. No other incentive was offered. The study was approved by the Institutional Review Board of the EADS.

\section{Study design}

During a 1-h group session 12 to 15 participants completed individually a set of questionnaires. Each group received a standardized introduction. Group sessions were held in a room separate from the workplace. To minimize biases arising from external or seasonal factors, we obtained all data within 5 days.

\section{Measures}

Instrument to assess exhaustion: vital exhaustion was assessed with the Shortened Maastricht Exhaustion Questionnaire (nine items) (Kopp et al. 1998), which was derived from the original Maastricht Questionnaire (21 items). The latter has been widely used to assess exhaustion in patients with myocardial infarction as well as in healthy subjects (Appels and Mulder 1988). Scores obtained from the short version correlate well with scores obtained using the original 21-item instrument $(\mathrm{r}=0.94 ; P<0.001 ; n=452)$ (Kopp et al. 1998). For purposes of this study, and in cooperation with the original authors of the instrument, we translated the nine items into German. In the original version possible answers are "no", scored as 0 ; indeterminate, which is marked as "?" and scored as 1 ; and "yes", scored as 2 . We used the same presentation of the answering format and the same scoring system, giving rise to a range of scores from 0 to 18 .

External validity criteria: a measure of functional health status and a symptom checklist were employed as external validity criteria for exhaustion. Functional health status was assessed by the SF-12, a short version developed from the original SF-36 Health Survey (Ware et al. 1993). The SF-12 (12 items) assesses the following eight dimensions: physical functioning, measuring the ability to perform a variety of daily activities and tasks that require physical effort (two items), role limitations due to physical health problems (two items), freedom from bodily pain (one item), general health perception (one item), vitality, measuring the perceived level of energy and fatigue (one item), social functioning (one item), role limitations due to emotional problems (two items), and mental health, assessing both positive and negative emotional states (two items). From these eight subscales a physical and a mental summary score is calculated.

The health symptom checklist consisted of a previously validated 20-item list (Burke 1999). Participants are asked whether they frequently suffer from any of the following complaints or symptoms at work or thereafter: pain (back, neck or shoulders, arms or hands, hips, knees, legs or feet), headache, retrosternal pain, dyspnea, cough, rhinitis, conjunctivitis, disturbed sleep, tiredness, gastrointestinal complaints, tinnitus or impaired hearing, irritability, blues, and dizziness. The answering format is "yes" (1 point) or "no" (no point). The maximum total score amounts to 20. Complaints are further grouped to three subscores: (1) respiratory and allergic complaints; (2) musculo-skeletal complaints; and (3) nervous system or psychosomatic complaints.

Work characteristics: the conditions of the working environment were assessed using the SALSA (Rimann and Udris 1997). The SALSA questionnaire assesses the subjective perception of work characteristics. The instrument has been validated in industrial workers with the same language and cultural background as the target population of this study. From these 52 items of the SALSA the following 13 scales are constructed: wholeness of work tasks (three items), responsibility and required qualification (four items), task variety (three items), qualification potential (three items), decision authority (three items), extent of participation (three items), excessive workload or qualitative demands (five items), lack of qualitative demands (three items), social support by co-workers (four items), supportive supervisor behavior (four items), adverse co-worker behavior (three items), adverse supervisor behavior (three items) and adverse physical work conditions (11 items). Each item is rated on a five-graded Likert scale ranging from "hardly ever" to "nearly always". Conceptually, the SALSA scales comprise pathogenic and salutogenic descriptors of decision latitude, psychological job demands and social support by co-workers and supervisors.

Baseline demographic data include gender, age, duration of employment, position (as an indicator of social economic status, comprising the four categories: manager, foreman, skilled worker or assistant/apprentice), form of payment (wage versus salary), and department. Employees on wage are paid an allocated time for each completed task up to a maximum of the contracted working time (usually $35 \mathrm{~h}$ per week). Thus, working faster does not increase payment. Delays negatively affect the wage unless employees spend extra (unpaid) overtime to complete the task. In contrast, subjects on salary receive a fixed monthly income. Typical examples of workers on wage are those employed in the manufacture of airplane parts, while typical examples of employees on salaries are secretaries, management or administration.

\section{Statistical analysis}

To test for selection bias we checked for differences in baseline demographic and employment data between the randomly chosen participants and the non-participating employees. Normally distributed continuous data were compared by Student's $t$-test, non- 
normally distributed data by the Kruskal-Wallis test, and categorical variables by the Chi-square test with continuity correction or Fisher's exact test, where appropriate. External validity was assessed by determining the correlation between vital exhaustion, the SF-12 mental summary score and the symptom score (including subscores)

The potential association between vital exhaustion and work characteristics was evaluated by partial correlation after potential confounding by baseline demographic variables was controlled for. Multivariable regression models with the exhaustion score as dependent variable were calculated to consider simultaneously the effects of baseline demographic variables, work characteristics and the heterogeneity between departments of the company. Position, form of payment (wage vs salary), department and gender were entered as class variables; age and the 13 SALSA subscale scores as continuous variables. For illustration of the effect size, we used multivariable logistic regression analysis to determine the odds ratios of variables being associated with scoring in the highest quartile of exhaustion scores compared with the lowest score. For this analysis, covariates were modeled as quartiles or dichotomous (below or above the median). For multivariable modeling, variables were entered in a stepwise fashion using $P=0.05$ as entry and retaining criterion. SF-12 summary scores were calculated using the SAS-code (version 6.12, SAS, Cary, North Carolina, USA) provided in the German SF-12/SF-36 manual (Bullinger 1998). Other analyses were carried out on SPSS (version 10.0, SPSS, Chicago, Illinois, USA).

\section{Results}

At the time of the study, the company had 1,760 employees. According to a computer-generated random number with stratification by department, 647 individuals were selected as eligible. Of these, $537(83 \%)$ participated. Table 1 compares the baseline demographic characteristics of the study population $(n=537)$ and non-participants $(n=1,223)$. Due to the pre-planned stratification rule, the study population comprised a higher proportion of foreman and managers. This intended deviation from the true proportion allowed for analysis of the impact of socio-economic status and of work characteristics specific to leadership positions.

\section{Vital exhaustion}

The mean vital exhaustion score amounted to 6.6 (standard deviation: 5.0, median: 6.0, interquartile range: $2-10$, range: $0-18)$. Cronbach's alpha for the nine items of the vital exhaustion scale was 0.83 , indicating good internal reliability of the instrument. The vital exhaustion score was positively associated with age (Pearson's $\mathrm{r}=0.15 ; P=0.001$ ), but not with gender $(\mathrm{r}=0.01 ; P=0.76)$. After controlling for age, we found no association with position $(\mathrm{r}=-0.01 ; P=0.78)$, or form of payment ( $\mathrm{r}=-0.07 ; P=0.104)$.

The vital exhaustion score correlated well with other subjective indicators of health: simple correlation was strong with the SF-12 mental health score (Pearson's $\mathrm{r}=-0.69 ; P<0.001$; lower scores on the SF-12 scale indicate poorer mental health), with the SF-12 physical health score $(\mathrm{r}=-0.33 ; P<0.001)$ and with the healthcomplaint list $(\mathrm{r}=0.45 ; P<0.001)$. A strong correlation existed with the subscale of nervous-system or psychosomatic complaints $(\mathrm{r}=0.65 ; P<0.001)$. The scores of the SF-12 physical and mental summary scales did not significantly differ between men and women $(P>0.5)$. Compared with the SF-12 German norm population ( $n=2914$; age 14 to over 70 years), the study participants had similar physical summary scores (present study: mean $=49.69$, standard deviation $=7.15$; norm population: mean $=49.03$, standard deviation $=9.35)$, but slightly lower mental summary scores (study mean = 49.62, standard deviation $=9.01$; norm population mean $=52.24$, standard deviation $=8.1$ ).

The nine-item vital exhaustion scale discriminated well between individuals and between departments with increased levels of vital exhaustion. Age and department explained $8 \%$ of the observed variance in vital exhaustion scores $\left(\mathrm{F}_{20 / 513}=2.2 ; P=0.002\right)$.

Relation between the vital exhaustion score and the SALSA scales

Work characteristics were assessed by the 52-item 13-scale SALSA questionnaire. The distribution and the mean scores of the SALSA scales in the present study population (data not shown) did not significantly differ from the original validation dataset $(n=1,655)$ for industrial and service populations with similar cultural
Table 1. Characteristics of the sample in comparison with potentially eligible individuals

\begin{tabular}{lccc}
\hline Characteristic & Participants & Non-participants & $P$ \\
\hline Number & 537 & 1223 & \\
Mean age (SD) in years & $41.0(10.3)$ & $41.6(11.4)$ & 0.22 \\
Mean duration (SD) of employment in years & $16.6(10.7)$ & $15.7(11.2)$ & 0.11 \\
Gender, male & $460(85.7 \%)$ & $1061(86.8 \%)$ & 0.22 \\
Position & $30(5.6 \%)$ & $14(1.2 \%)$ & $<0.001^{\mathrm{a}}$ \\
$\quad$ Manager & $64(11.9 \%)$ & $69(5.6 \%)$ & $<0.001^{\mathrm{a}}$ \\
$\quad$ Foreman & $443(82.5 \%)$ & $1140(93.2 \%)$ & $<0.001^{\mathrm{a}}$ \\
Worker & $287(53.4 \%)$ & $876(71.6 \%)$ & $<0.001^{\mathrm{a}}$ \\
On wage $^{\mathrm{b}}$ & &
\end{tabular}

${ }^{a}$ Differences in proportions are significant because of the intended stratified sampling method

${ }^{\mathrm{b}}$ Individuals are paid an allocated time for each completed task up to a maximum of the contracted time (usually $35 \mathrm{~h}$ per week). Thus, working faster does not increase the wage, but delays negatively affect the wage unless the employee spends extra overtime. Subjects on a salary receive a fixed monthly income 
and language background (Rimann and Udris 1997). Both unadjusted correlation and partial correlation after age had been controlled for showed that the vital exhaustion scores were significantly correlated with most of the 13 SALSA subscales (Table 2).

Multivariable regression analysis with stepwise inclusion showed that seven variables explained $29 \%$ of the observed variance scores. These variables were department, age (positive association, +) and five SALSA scales, namely: excessive workload or qualitative demands $(+)$, adverse co-worker behavior $(+)$, adverse physical work conditions $(+)$, qualification potential $(-)$, and social support by co-worker (-). Table 3 presents the results of multivariable modeling.

Table 4 presents the data from bivariate and multivariable logistic regression analyses for scoring in the highest quartile of vital exhaustion ( $>10$ points) vs scoring in the lowest quartile ( $<3$ points). Most SALSA variables as well as age, but not position (socio-economic status) or gender showed a significant association in bivariate models. The multivariable model retained five of the SALSA scales plus age. The model had a high predictive accuracy (area under the receiver operating characteristic curve $=0.86$ ) and was well calibrated (Hosmer-Lemeshow goodness-of-fit test $P=0.40$ ). Besides excessive workload or qualitative demands and adverse physical working conditions, adverse co-worker behavior was strongly associated with exhaustion scores above 10 (Table 4). A post-hoc analysis using a median split for SALSA scales instead of the pre-planned quartile split presented in Table 4 showed that adverse co-worker behavior had the strongest association with high exhaustion of all variables $\left(\mathrm{OR}_{\text {adj }} 4.1 ; 95 \%\right.$ CI $2.1-$ 8.0). Further variables increasing the risk of high exhaustion scores were: adverse physical work conditions, quantitative work overload, and age. Qualification potential and social support by co-workers exerted a protective effect. $\mathrm{OR}_{\mathrm{adj}}$ for quartile modeling of the independent variables are presented in Table 4.

\section{Discussion}

In this study we assessed levels of exhaustion in 537 employees of a highly competitive sector of the manufacturing industry. We further aimed to elucidate the association between vital exhaustion and pathogenic or salutogenic work conditions in healthy industrial workers. The German version of the nine-item short form of the Maastricht Vital Exhaustion Questionnaire (a translation from the Dutch and English version by the authors (1999), unpublished) showed a good ability to identify individuals or groups of employees with high levels of exhaustion. The vital exhaustion score correlated well with external criteria for validity, namely the mental summary score of the SF-12 and the subscale for nervous-system and psychosomatic complaints on a health symptom checklist.

Vital exhaustion, a state of unusual tiredness, increased irritability and feelings of demoralization, was
Table 2. Correlation of vital exhaustion with SALSA subscales, crude analysis and analysis adjusted for age

Table 3. Results from multivariable linear regression modeling

\begin{tabular}{llc}
\hline Vital exhaustion & & \\
\hline Parameter & Simple Pearson correlation & $\begin{array}{l}\text { Partial correlation } \\
\text { controlling for age }\end{array}$ \\
\hline Task variety & $-0.14(P \leq 0.005)$ & $-0.17(P \leq 0.005)$ \\
Qualification potential & $-0.24(P \leq 0.005)$ & $-0.25(P \leq 0.005)$ \\
Decision authority & $-0.08(P=0.06)$ & $-0.14(P \leq 0.005)$ \\
Responsibility and required qualification & $-0.04(P=0.40)$ & $-0.07(P=0.09)$ \\
Wholeness of working tasks & $-0.19(P \leq 0.005)$ & $-0.24(P \leq 0.005)$ \\
Social support by co-worker & $-0.22(P \leq 0.005)$ & $-0.22(P \leq 0.005)$ \\
Supportive supervisor behavior & $-0.24(P \leq 0.005)$ & $-0.25(P \leq 0.005)$ \\
Extent of participating & $-0.25(P \leq 0.005)$ & $-0.26(P \leq 0.005)$ \\
Excessive workload or qualitative demands & $0.32(P \leq 0.005)$ & $0.31(P \leq 0.005)$ \\
Lack of qualitative demands & $0.21(P \leq 0.005)$ & $0.23(P \leq 0.005)$ \\
Adverse physical work conditions & $0.31(P \leq 0.005)$ & $0.33(P \leq 0.005)$ \\
Adverse supervisor behavior & $0.19(P \leq 0.005)$ & $0.20(P \leq 0.005)$ \\
Adverse co-worker behavior & $0.33(P \leq 0.005)$ & $0.33(P \leq 0.005)$ \\
\hline
\end{tabular}

\begin{tabular}{|c|c|c|c|c|}
\hline $\begin{array}{l}\text { Parameter } \\
\text { Model including both genders }\end{array}$ & $\begin{array}{l}\mathrm{r}^{2} \\
0.29\end{array}$ & $\begin{array}{l}\text { df } \\
25\end{array}$ & $\begin{array}{l}F \\
7.67\end{array}$ & $\begin{array}{l}P \\
<0.001\end{array}$ \\
\hline Variables of the model including both genders & Partial $r^{2}$ & & $P$ & \\
\hline Excessive workload or qualitative demands & 0.089 & & $<0.001$ & \\
\hline Department & 0.060 & & $<0.001$ & \\
\hline Age & 0.060 & & 0.004 & \\
\hline Adverse co-worker behavior & 0.048 & & 0.036 & \\
\hline Adverse physical work conditions & 0.042 & & $<0.001$ & \\
\hline Qualification potential & 0.021 & & 0.004 & \\
\hline Social support by co-worker & 0.010 & & 0.013 & \\
\hline
\end{tabular}


Table 4. Results from multivariable logistic regression analysis modeling the probability to score in the highest quartile of the vital exhaustion score ( $>10$ points) vs scoring in the lowest quartile $(<3$ points). Except for age, independent variables are modeled as dummy variables with quartiles as strata. $\mathrm{OR}_{\mathrm{adj}}$ are presented for the second, third and top quartile, compared with the lowest quartile. Higher scores on a SALSA subscale indicate higher expression of that factor

\begin{tabular}{|c|c|c|}
\hline Variable & $\begin{array}{l}\text { Crude odds } \\
\text { ratio }(95 \% \mathrm{CI})\end{array}$ & $\mathrm{OR}_{\text {adj }}(95 \% \mathrm{CI})$ \\
\hline \multicolumn{3}{|c|}{ Excessive workload or qualitative demands } \\
\hline Lowest quartile & 1.0 & 1.0 \\
\hline 25 th to 50 th percentile & $2.6(1.2-5.4)$ & $2.3(0.90-5.8)$ \\
\hline 50 th to 75 th percentile & $3.7(1.9-7.4)$ & $2.4(0.99-5.7)$ \\
\hline Highest quartile & $15.3(6.1-38.3)$ & $7.5(2.4-23.4)$ \\
\hline \multicolumn{3}{|c|}{ Adverse co-worker behavior } \\
\hline Lowest quartile & 1.0 & 1.0 \\
\hline 25 th to 50 th percentile & $1.2(0.55-2.7)$ & $0.86(0.33-2.3)$ \\
\hline 50 th to 75 th percentile & $4.1(2.1-7.9)$ & $2.7(1.1-6.6)$ \\
\hline Highest quartile & $17.6(6.6-47.1)$ & $4.8(1.4-16.1)$ \\
\hline \multicolumn{3}{|c|}{ Adverse physical working conditions } \\
\hline Lowest quartile & 1.0 & 1.0 \\
\hline 25 th to 50 th percentile & $3.1(1$. & $2.2(0.76$ \\
\hline 50 th to 75 th & 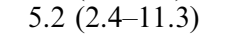 & $4.5(1.7-12)$ \\
\hline Highest quartile & $7.4(3.2-17.1)$ & $6.9(2.2-21.3)$ \\
\hline \multicolumn{3}{|l|}{ Qualification potential } \\
\hline Lowest quartile & 1.0 & 1.0 \\
\hline 25 th to 50 th percentile & $0.37(0.19-0.72)$ & $0.43(0.17-1.1)$ \\
\hline 50 th to 75 th percentile & $0.36(0.18-0.73)$ & $0.40(0.15-1.0)$ \\
\hline Highest quartile & $0.18(0.08-0.39)$ & $0.32(0.11-0.97)$ \\
\hline \multicolumn{3}{|c|}{ Social support by co-workers } \\
\hline Lowest quartile & 1.0 & 1.0 \\
\hline 25 th to 50 th percentile & $0.37(0.18-0.74)$ & $0.63(0.26-1.5)$ \\
\hline 50 th to 75 th percentile & $0.17(0.08-0.35)$ & $0.22(0.08-0.59)$ \\
\hline Highest quartile & $0.2(0.09-0.42)$ & $0.34(0.13-0.99)$ \\
\hline $\begin{array}{l}\text { Age (per increment } \\
\text { of } 10 \text { years) }\end{array}$ & $1.3(1.0-1.6)$ & $1.6(1.1-2.3)$ \\
\hline
\end{tabular}

originally described as a precursor of acute coronary events (Appels 1990; Appels et al. 1987). More recently, vital exhaustion has been identified as a long-term risk factor for cardiovascular disease (Ad Appels (2001), personal communication; Cole et al. 1999). The median scores for vital exhaustion increased with age. However, employees younger than 30 years of age accounted for most of this association. Contrary to the data from the literature, in this study population exhaustion failed to retain a significant association with socio-economic status, gender or being on wage vs being on salary (Baum et al. 1999; Feeney et al. 1998; Taylor et al. 1997). We excluded the possibility of negative confounding by multivariable modeling. The most likely explanation is that employees in this aircraft manufacturing plant represent a highly skilled subgroup of industrial workers with less income inequity.

The most striking finding was that five work characteristics, namely excessive workload or qualitative demands, adverse physical work conditions, qualification potential, adverse co-worker behavior, and social support by co-workers plus age explained nearly a third of the observed variance in exhaustion scores. Factors associated with low exhaustion were: social support by co-workers, and qualification potential. Participants reporting high social support by co-workers were three times less likely to feel exhausted than were subjects perceiving little or no social support by co-workers. The primary "adverse" work characteristics, which showed an association with high levels of exhaustion were: quantitative workload, adverse physical working conditions and adverse co-worker behavior. Employees with scores for adverse co-worker behavior in the top quartile were nearly five times more likely to yield high exhaustion scores (above 10) than participants perceiving little or no adverse co-worker behavior. This finding is important because one of the consistent characteristics of vital exhaustion is increased irritability. In cases of overload or potential conflict, individuals with increased irritability are more likely to show adverse behavior, with potential withdrawal or exacerbation to open confrontation. This may induce adverse co-worker behavior, leading to a vicious circle, perpetuating exhaustion.

If the nine-item Vital Exhaustion Questionnaire used in this study is supplemented by the 12-item SF-12 questionnaire, large populations can be screened for exhaustion and physical and mental health status within fewer than 10 min per participant. This allows cost-effective identification of individuals or groups at risk, who warrant further in-depth assessment. Vital exhaustion does not only represent a long-term risk factor for adverse health outcomes; exhaustion may - like burnout in healthcare professionals - impair job performance. Thus, high levels of exhaustion should be viewed as an alarm signal of impending breakdown of human capital. Therefore, industrial organizations aiming to sustain high productivity should aim to identify individuals or groups with high levels of exhaustion. In the long run, eliminating causes of exhaustion may be an important measure to increase productivity.

Several potential caveats of this investigation require consideration. First, recall bias and over-reporting of negative work conditions or health may have introduced a bias overestimating the level of exhaustion, the number of health complaints and the perception of adverse work conditions. While this bias may have systematically distorted the absolute scores, it was less likely to affect the strength or direction of the observed associations. Second, we did not objectively assess working conditions. However, self-reported job strain appears to be a better predictor of long-term health outcomes than objective indices of work stress (Hammar et al. 1994; Johnson et al. 1989). Third, we cannot exclude residual confounding by health-related behavior such as smoking, physical exercise or alcohol consumption (Michael et al. 1999). Considering the small number of participating women, and the uneven distribution of women across departments, we could not exclude residual confounding or selection biases. Therefore, we refrained from presenting subgroup analysis for gender. Finally, the cross-sectional nature of our study does not allow inferences about the causality or pathways underlying the observed associations. Thus, we do not know 
whether ameliorating adverse working conditions will ultimately affect levels of exhaustion. This can only be elucidated by long-term follow-up of participants and of changes that are introduced - a study that is under way.

In conclusion, we demonstrated that the nine-item short form of the Maastricht Questionnaire is associated with specific adverse work characteristics, namely adverse co-worker behavior, adverse physical work conditions and high workload or qualitative demands, and age. Qualification potential and social support by coworkers showed a protective association. The instrument may allow for rapid screening of large working populations and for identification of individuals or groups at risk. The identified work characteristics, which were related to exhaustion, may represent underlying risk and protective factors.

Acknowledgements We are indebted to the employees of the EADS Deutschland $\mathrm{GmbH}$, Werk Augsburg, for dedicated participation in this study. In particular we wish to thank Gudrun Baumgärtel and Gerhard Schipfel for assistance in conducting the study. Furthermore, we want to thank Prof. Ralf Schwarzer for important contributions to the design. The study was partly funded by the EADS Deutschland GmbH, Werk Augsburg.

\section{References}

Appels A (1990) Mental precursors of myocardial infarction. Br J Psychiatry 156:465-471

Appels A (1997) Why do imminent victims of a cardiac event feel so tired? Int J Clin Pract 51:447-450

Appels A (1999) Inflammation and the mental state before an acute coronary event. Ann Med 31 [Suppl 1]:41-44

Appels A, Mulder P (1988) Excess fatigue as a precursor of myocardial infarction. Eur Heart J 9:758-764

Appels A, Schouten E (1991) Burnout as a risk factor for coronary heart disease. Behav Med 17:53-59

Appels A, Hoppener P, Mulder P (1987) A questionnaire to assess premonitory symptoms of myocardial infarction. Int $\mathbf{J}$ Cardiol 17:15-24

Baum A, Garofalo JP, Yali AM (1999) Socioeconomic status and chronic stress. Does stress account for SES effects on health? Ann N Y Acad Sci 896:131-144

Bullinger MK (1998) SF-36 Fragebogen zum Gesundheitszustand. Hogrefe, Göttingen

Burke I (1999) BiBB/IAB Strukturerhebung "Erwerb und Verwertung beruflicher Qualifikation von Erwerbstätigen".
München: Bundesinstitut für Berufsbildung/Institut für Arbeitsmarkt und Berfusforschung der Bundesanstalt für Arbeit

Cole SR, Kawachi I, Sesso HD, Paffenbarger RS, Lee IM (1999) Sense of exhaustion and coronary heart disease among college alumni. Am J Cardiol 84:1401-1405

Demerouti E, Bakker AB, Nachreiner F, Schaufeli WB (2000) A model of burnout and life satisfaction amongst nurses. J Adv Nurs 32:454-64

Edwards D, Burnard P, Coyle D, Fothergill A, Hannigan B (2000) Stress and burnout in community mental health nursing: a review of the literature. J Psychiatr Ment Health Nurs 7:7-14

Feeney A, North F, Head J, Canner R, Marmot M (1998) Socioeconomic and sex differentials in reason for sickness absence from the Whitehall II Study. Occup Environ Med 55:91-98

Hammar N, Alfredsson L, Theorell T (1994) Job characteristics and the incidence of myocardial infarction. Int $\mathbf{J}$ Epidemiol $23: 277-284$

Hannigan B, Edwards D, Coyle D, Fothergill A, Burnard P (2000) Burnout in community mental health nurses: findings from the all-Wales stress study. J Psychiatr Ment Health Nurs 7:127-134

Johnson JV, Hall EM, Theorell T (1989) Combined effects of job strain and social isolation on cardiovascular disease morbidity and mortality in a random sample of the Swedish male working population. Scand J Work Environ Health 15:271-279

Kopp MS, Falger PR, Appels A, Szedmak S (1998) Depressive symptomatology and vital exhaustion are differentially related to behavioral risk factors for coronary artery disease. Psychosom Med 60:752-758

Landsbergis PA, Cahill J, Schnall P (1999) The impact of lean production and related new systems of work organization on worker health. J Occup Health Psychol 4:108-130

Leiter MP, Harvie PL (1996) Burnout among mental health workers: a review and a research agenda. Int J Soc Psychiatry 42:90-101

Maslach C, Schaufeli WB, Leiter MP (2001) Job burnout. Annu Rev Psychol 52:397-422

Michael YL, Colditz GA, Coakley E, Kawachi I (1999) Health behaviors, social networks, and healthy aging: cross-sectional evidence from the Nurses' Health Study. Qual Life Res 8:711-722

Payne N (2001) Occupational stressors and coping as determinants of burnout in female hospice nurses. J Adv Nurs 33:396-405

Rimann M, Udris I (1997) Subjektive Arbeitsanalyse: Der Fragebogen SALSA. In: Strohm O, Ulich E (eds) Unternehmen arbeitspsychologisch bewerten. vdf Hochschulverlag, Zurich

Taylor SE, Repetti RL, Seeman T (1997) Health psychology: what is an unhealthy environment and how does it get under the skin? Annu Rev Psychol 48:411-447

Ware J, Snow K, Kosinski M, Gandek B (1993) SF-36 health survey: manual and interpretation guide. New England Medical Center, Health Institute, Boston

Weber A, Jaekel-Reinhard A (2000) Burnout syndrome: a disease of modern societies? Occup Med (Lond) 50:512-517 